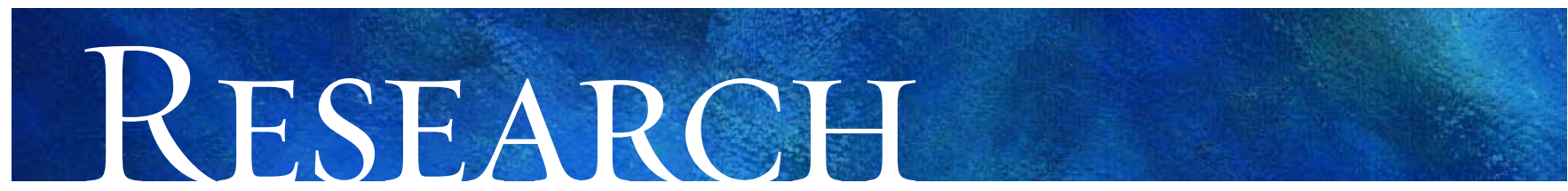

\title{
Type 2 diabetes does not increase risk of depression
}

\author{
Lauren C. Brown, Sumit R. Majumdar, Stephen C. Newman, Jeffrey A. Johnson
}

$\infty$

See related article page 47

\section{ABSTRACT}

Background: Although diabetes mellitus has a strong association with the presence of depression, it is unclear whether diabetes itself increases the risk of developing depression. The objective of our study was to evaluate whether people with diabetes have a greater incidence of depression than those without diabetes.

Methods: We conducted a population-based retrospective cohort study using the administrative databases of Saskatchewan Health from 1989 to 2001 . People older than 20 years with newly identified type 2 diabetes were identified by means of diagnostic codes and prescription records and compared with a nondiabetic cohort. Depression was ascertained via diagnostic codes and prescriptions for antidepressants. Cox regression analysis was used to estimate hazard ratios (HRs) and 95\% confidence intervals (Cls) after adjusting for age, sex, frequency of visits to physicians and presence of comorbidities.

Results: We identified 31635 people with diabetes and 57141 without. Those with diabetes were older (61.4 v. $46.8 \mathrm{yr}$; $p<0.001$ ), were more likely to be male (55.4\% v. $49.8 \% ; p$ $<0.001$ ) and had more physician visits during the year after their index date (mean 14.5 v. 5.9; $p<0.001$ ). The incidence of new-onset depression was similar in both groups $(6.5 \mathrm{v}$. 6.6 per 1000 person-years among people with and without diabetes, respectively). Similarity of risk persisted after controlling for age, sex, number of physician visits and presence of prespecified comorbidities (adjusted HR 1.04, 95\% Cl 0.941.15). Other chronic conditions such as arthritis (HR 1.18) and stroke (HR 1.73) were associated with the onset of depression.

Interpretation: Using a large, population-based administrative cohort, we found little evidence that type 2 diabetes increases the risk of depression once comorbid diseases and the burden of diabetes complications were accounted for.

CMAJ 2006;175(I):42-6

T ncreasing prevalences of chronic medical conditions are a growing health and economic burden. Type 2 diabetes, for example, shortens life, mostly through comorbid cardiovascular disease. ${ }^{1-4}$ Another comorbidity associated with diabetes that is increasingly recognized is depression. Several investigations ${ }^{5-8}$ have documented that people with diabetes experience depression from I. 3 to 3 times as often as those without the disorder. Many of these studies are limited by their cross-sectional design, however, and have not addressed the temporal relation between the onsets of these 2 conditions.

Depression itself is a disabling illness leading to considerable illness and early death., ${ }^{9,10}$ When associated with diabetes, depression increases the risks of work loss, ${ }^{11}$ functional disability, ${ }^{11,12}$ and micro- ${ }^{13}$ and macrovascular complications, ${ }^{14}$ and adds to health care costs. ${ }^{13,15}$ Diabetes with comorbid depression is also linked with poorer adherence to medications and self-care activities such as self-monitoring of blood glucose levels and adhering to a proper diet and exercise program. ${ }^{16-19}$ Perhaps most importantly, depressed patients with diabetes die earlier than other people, irrespective of their sociodemographic variables, lifestyle or health status. ${ }^{20}$

Several prospective studies have evaluated the risk of diabetes in those with previous depression. ${ }^{21-31}$ Most reported an increased risk of diabetes associated with a history of depression or depressive symptoms, but often only in selected subpopulations. ${ }^{21-24,26-28,30,31}$ Carnethon and colleagues, ${ }^{28}$ for example, found that the increased risk was limited to those with less education; Arroyo's group ${ }^{22}$ studied only women; and Palinkas and associates ${ }^{26}$ evaluated middle-class individuals aged 50 years and older. We recently conducted a large, population-based, nested case-control study ${ }^{21}$ that suggested an association between a history of depression and the onset of type 2 diabetes, but this increased risk was limited to people no older than 50 years.

Little information is currently available on the obverse of that temporal chain: the incidence of depression among people who have diabetes. Such knowledge could influence clinical practice by suggesting who would most effectively be screened for depression and by evaluating ways to prevent people with diabetes from becoming depressed, in order to decrease both the patients' risk of complications and the cost of the ensuing treatments. We therefore conducted a population-based retrospective cohort study to evaluate the incidence of new-onset depression among people with diabetes, compared with those who do not have diabetes.

\section{Methods}

Ethics approval to conduct this study was granted from the Health Research Ethics Board at the University of Alberta.

Saskatchewan Health databases include information on most residents (99\%) of the province of Saskatchewan (pop- 
ulation about I million). ${ }^{32}$ Patients whose information is not included in the Saskatchewan Health databases include those with federally funded health care, such as members of the Royal Canadian Mounted Police and the Canadian Forces. ${ }^{32}$ Some $90 \%$ of the covered population are eligible for prescription drug benefits. Those ineligible include registered First Nations peoples, who receive prescription benefits through a federal program. Data from 4 different sets of data files were used in this study: health registration, outpatient prescription drug, medical services and hospital separation files. The data files are linkable via personal health numbers and therefore provide demographic information, prescription drug usage and diagnostic codes for outpatient visits and hospital stays.

Individuals with incident cases of diabetes and randomly selected people without diabetes were identified between January I, I992 and December 3I, 2000 (the index period). To ensure that the cases of diabetes we identified were of new onset, we applied a 3-year diabetes washout period: people who met the case definition between January I, 1989 and December 3I, I99I were excluded. All subjects were followed until death, termination of coverage (e.g., because of departure from the province) or December 3I, 200I.

Included in this study were residents of Saskatchewan who were 20 years of age or older and eligible for prescription drug benefits during the study period. Two study groups were identified: people with diabetes and a cohort of people without diabetes for comparison.

People with diabetes were identified within the index period according to the established case definition for the National Diabetes Surveillance System (NDSS): ${ }^{33-35}$ if they had 2 or more physician service claims for diabetes (International Classification of Disease, 9th Revision [ICD-9] code 250) within a 2-year period, or one or more hospitalizations with a diabetes code as the primary, secondary or tertiary diagnosis. Dispensation for an oral antidiabetic agent (Appendix I) was used to limit the sample to type 2 diabetes. The study index date for each case was identified as the date either that the NDSS criteria were met or of the first dispensation of an oral antidiabetic agent, whichever came first. Women with service claims for gestational diabetes (ICD-9 648.8) were excluded.

Subjects without diabetes (i.e., who did not meet the definition for having diabetes during the washout or index periods) were identified by randomly selecting subjects from the "nondiabetes" population. For each subject with diabetes, 2 people without diabetes were chosen within the same index year and assigned the same study index date as their respective diabetes subject, but not matched to the subject for any clinical or demographic characteristic. In all analyses and calculations of hazard ratios (HRs), the diabetes-absent cohort served as the reference group.

To identify episodes of depression within the administrative databases we used a composite definition that had previously been validated ${ }^{36}$ in the administrative databases of Saskatchewan Health: a prescription for an antidepressant medication along with any of three ICD-9 codes for depressive disorders $(296,309$ or $3 \mathrm{II})$ within a 6 -month reference period (i.e., \pm 3 months) from the physician services records. This criterion yielded a sensitivity of $71 \%$ and a specificity of
$85 \%$ for identifying people with depression..$^{36}$ To capture only new-onset cases of depression, individuals with a depressive episode within up to 3 years before the study index date were excluded from the analysis. Because information from the physician services record was used in the composite definition, all people identified as having depression were identified through community-based physician visits rather than through hospital admission for depression.

Subjects with an incident depressive episode were then evaluated for continuation of antidepressant therapy. Those with at least 1 subsequent dispensation of antidepressant medication were considered to have ongoing depression and were included in the analysis. Those dispensed an antidepressant only once were considered to have a limited depressive episode and were excluded from the analysis.

We assessed the incidence of new-onset depression and initially estimated the unadjusted HRs and $95 \%$ confidence intervals (CIs) using Cox regression, with time until depression as the dependent variable and presence of diabetes as the main independent variable. We then used multivariable Cox regression to control for potential confounding by age, sex and number of physician visits during the year after the index date. To control for the nonlinear relation between age and depression, we used a mean-centred quadratic function. ${ }^{37}$ Number of physician visits in the year after the study index date was used to control for both comorbidity and the potential influence of medical surveillance bias among people diagnosed with diabetes. ${ }^{38}$ To better meet the assumptions of proportional hazards, the number of physician visits was categorized into quarters (0 or 1 visit, 2-6 visits, 7-12 visits, and 13 or more visits during the year after the study index date) by quartile. We also included information on insulin use as a measure of diabetes severity.

Several chronic medical conditions have been shown to be associated with an increased risk of depression. ${ }^{39-41}$ We therefore preselected 5 comorbidities, identified within 2 years after the study index date, to be included in our analyses: arthritis, cancer, cerebrovascular disease (stroke), coronary artery disease and peripheral arterial disease. Patients with arthritis were identified if they had been admitted to hospital or visited a physician because of a disease of the musculoskeletal system or connective tissue (ICD-9 codes 710-739). Cancer was identified via hospital admissions or physician visits for neoplasm (ICD-9 codes I40-239); cerebrovascular disease, through those for stroke or transient ischemic attack (ICD-9 codes 430-438); and coronary artery disease, via those for myocardial infarction, angina, cardiomyopathy, arrhythmia, congestive heart failure, cardiomegaly (ICD-9 codes 4IO-4I4 or 425-429), coronaryartery bypass graft, angioplasty or a dispensation of nitrates. ${ }^{42}$ Peripheral arterial disease was noted for subjects who were dispensed pentoxifylline or who had a lower limb amputated. ${ }^{42}$

\section{Results}

We identified 92677 subjects ( 33257 with diabetes and 59420 without) during the index period. Of these, 3901 people were excluded (I622 [4.9\%] with diabetes and 2279 [3.8\%] without) because of a history of depression before their study index date. ${ }^{21}$ This left 88776 subjects, of whom 3I 635 were 
Table 1: Demographic information for study participants with and without diabetes

\begin{tabular}{|c|c|c|c|c|}
\hline Characteristic & \multicolumn{2}{|c|}{ Diabetes, $n=31635$} & \multicolumn{2}{|c|}{ No diabetes, $n=57141$} \\
\hline Sex, male, \% & 47.2 & 55.7 & 36.7 & 50.2 \\
\hline Age, mean (range) [SD], yr & $58.3(21-91)$ [16.7] & $61.5(20-95)[15.2]$ & $44.5(20-93)[16.9]$ & $46.9(20-94)[18.2]$ \\
\hline $\begin{array}{l}\text { Physician visits during } 1 \mathrm{yr} \text { after } \\
\text { index date, mean (range) [SD] }\end{array}$ & $19.1(0-200)[16.1]$ & $14.3(0-209)[11.4]$ & $9.1(0-81) \quad[9.3]$ & $5.8(0-168) \quad[8.1]$ \\
\hline \multicolumn{5}{|l|}{ Comorbidities, \% } \\
\hline Arthritis & 51.5 & 46.3 & 42.1 & 34.0 \\
\hline Cancer & 17.8 & 16.9 & 11.6 & 10.3 \\
\hline Coronary artery disease & 27.5 & 28.9 & 8.7 & 8.8 \\
\hline
\end{tabular}

Note: $\mathrm{SD}=$ standard deviation .

identified as having new-onset diabetes. The mean age of the entire cohort was 52 years (median $5 \mathrm{I}$, range 20-95 years); $48 \%$ were female. The whole cohort had an average of 8.9 physician visits (range o-209) during the year after their study index date. Among people with diabetes, the mean age was 6I.4 years (range 20-95 yr) and 45\% were female (Table I). The mean number of physician visits for people with diabetes within a year of their index date was 14.5 (range 0-209). Among those with diabetes, $47 \%$ had arthritis, $17 \%$ cancer, $6.4 \%$ a history of stroke, $28.9 \%$ coronary artery disease and I. $3 \%$ peripheral arterial disease; $12.6 \%$ used insulin.

The nondiabetes cohort had a mean age of 46.8 (range 2094 ) years; $50.2 \%$ were female. Their average number of physician visits in the year after the study index date was 5.9 (range o-I68). Presence of comorbidities was less common in the nondiabetes cohort, with $34.9 \%$ having arthritis, $10.5 \%$ cancer, $\mathrm{r} .8 \%$ a history of stroke, $8.9 \%$ coronary artery disease and $0.3 \%$ peripheral arterial disease.

The average follow-up for the entire cohort was 4.5 years (standard deviation [SD] 2.9; Table I), during which a total of 2534 episodes of depression were identified. The unadjusted incidence rate of depression in the diabetes and nondiabetes cohorts was similar (6.5 and 6.6 per Iooo person-years, respectively). The unadjusted HR was I.Io (Table 2). Multivariable adjustment for sex, age, physician visits and preselected comorbidities yielded a hazard ratio of 1.04. Of note, the 5 symptomatic comorbidities we examined were each associated with an increase in the risk of depression, although only arthritis, stroke and peripheral arterial disease achieved statistical significance in multivariable models (Table 2).

\section{Interpretation}

After adjustments for age, sex, number of physician visits and the presence of other comorbidities in this large, population- based, retrospective cohort study, newly identified type 2 diabetes was not associated with an increased risk of incident depression. It is possible, however, that the onset of symptomatic long-term macrovascular complications, such as coronary disease, stroke and peripheral arterial disease, can lead to depression in people with type 2 diabetes. ${ }^{43,44}$ Numerous cross-sectional studies have shown an association between depression and diabetes, and prospective observational studies have found an increased risk of diabetes among people experiencing depression or symptoms that are highly depressive. ${ }^{5-8,21-31}$ Our results here are in accord with the conclusion that depression increases the risk of diabetes, rather than vice-versa.

As with all studies that use administrative data to evaluate a research question, this study has its limitations. Our figures may underestimate the prevalence of all symptomatic conditions, including undiagnosed diabetes, because patients with milder symptoms are less likely to seek treatment or be admitted to hospital and would not be captured in the databases. The stigma associated with mental illness makes many people reluctant to seek treatment for depressive disorders, which would lead to an underestimation of the number of subjects with depression. The set of criteria we used to identify people with depression had a sensitivity of $7 \mathrm{I} \%$ and a specificity of $85 \%$; it is therefore possible that people in this data set undergoing depression were not identified as such, and that those without depression were attributed depression. ${ }^{36}$ Despite a maximum intended follow-up of 10 years, the mean length of follow-up in our cohort was only 4.5 years, possibly too short to observe depression subsequent to new-onset diabetes. And although we included use of insulin as a marker for diabetes severity in the statistical analysis, the lack of clinical data typical of administrative databases limited our ability to investigate the relation of severity of diabetes or comorbidities with depression. As mentioned, as diabetes progresses 
Table 2: Unadjusted and adjusted* risk of developing depression

Hazard ratio ( $95 \%$ confidence interval)

\begin{tabular}{|lcc|}
\hline Factor & \multicolumn{1}{c}{ Unadjusted } & Adjusted \\
\hline Diabetes & $1.10(1.01-1.19)$ & $1.04(0.94-1.15)$ \\
\hline Sex (male) & $0.64(0.59-0.70)$ & $0.73(0.67-0.79)$ \\
\hline Age, yr & & \\
\hline Mean-centred & $1.00(0.99-1.00)$ & $0.99(0.99-0.99)$ \\
\hline Mean-centred squared & $1.00(1.00-1.00)$ & $1.00(1.00-1.00)$ \\
\hline Physician visits in 1 yr ${ }^{\dagger}$ & & \\
\hline $0-1$ (reference group) & 1 & 1 \\
\hline $2-6$ & $1.11(0.98-1.26)$ & $1.03(0.90-1.17)$ \\
\hline $7-12$ & $1.50(1.32-1.70)$ & $1.41(1.23-1.63)$ \\
\hline 13 or more & $2.00(1.77-2.25)$ & $1.81(1.56-2.10)$ \\
\hline Comorbidities in 2 yr $\dagger$ & & \\
\hline Arthritis & $1.33(1.23-1.47)$ & $1.18(1.09-1.29)$ \\
\hline Cancer & $1.21(1.08-1.35)$ & $1.07(0.96-1.21)$ \\
\hline Vascular disease & & \\
\hline Coronary artery & $1.09(0.98-1.21)$ & $1.06(0.93-1.19)$ \\
\hline Cerebrovascular & $1.51(1.24-1.84)$ & $1.73(1.41-2.13)$ \\
\hline Peripheral arterial & $1.87(1.26-2.77)$ & $1.79(1.20-2.66)$ \\
\hline Insulin use & $1.34(1.16-1.55)$ & $1.11(0.95-1.30)$ \\
\hline
\end{tabular}

*Adjusted for all the variables listed in the table.

tPeriod begins at the study index date.

and complications develop, a patient may be at greater risk of depression than someone without diabetes, especially given the significantly increased risk of depression that we observed among people with arthritis, stroke and peripheral arterial disease.

This large, population-based cohort study demonstrated that people who are diagnosed with type 2 diabetes are at no greater risk of developing subsequent depression than people without diabetes. Based on these findings, people with type 2 diabetes and no previous history of depression require no more screening for depression than the overall general population seen in primary care, and should therefore be assessed on a case-by-case basis. Our results do suggest, however, that people with diabetes who have developed symptomatic comorbidities such as stroke or peripheral arterial disease may be at increased risk of depression: greater attention to such patients is likely warranted.

\section{This article has been peer reviewed.}

From the Departments of Public Health Sciences (Brown, Majumdar, Newman, Johnson), Medicine (Majumdar) and Psychiatry (Newman), University of Alberta, and the Institute of Health Economics (Brown, Majumdar, Johnson), Edmonton, Alta.

\section{Competing interests: None declared.}

Contributors: All authors participated in the conception of the study question, the design of the analysis and the preparation of the manuscript. Lauren Brown conducted the analysis and prepared the initial drafts of the manuscript. Jeffrey Johnson obtained the original data set.
Acknowledgements: This study was funded by a grant from the Canadian Institutes of Health Research (CIHR) and by a New Emerging Team (NET) grant to the Alliance for Canadian Health Outcomes Research in Diabetes (ACHORD). The ACHORD NET grant is sponsored by the Canadian Diabetes Association, the Heart and Stroke Foundation of Canada, The Kidney Foundation of Canada, and the CIHR's Institute of Nutrition, Metabolism and Diabetes and Institute of Circulatory and Respiratory Health.

Sumit Majumdar holds a Population Health Investigator Award through the Alberta Heritage Foundation for Medical Research (AHFMR) and is a New Investigator of CIHR. Jeffrey Johnson is a Health Scholar AHFMR and a Canada Research Chair in Diabetes Health Outcomes. Lauren Brown is supported by a Full-time Health Research Studentship award from AHFMR.

This study was based in part on de-identified data provided by the Saskatchewan Department of Health. The interpretation and conclusions contained herein do not necessarily represent those of the Government of Saskatchewan or the Saskatchewan Department of Health.

\section{REFERENCES}

I. Barrett-Connor E, Pyörälä K. Long-term complications: diabetes, coronary heart disease, stroke and lower extremity arterial disease. In: Ékoé J-M, Zimmet P, Williams R, eds. The epidemiology of diabetes mellitus: an international perspective. Chichester, UK: John Wiley \& Sons, Ltd; 200I. p. 30I-I9.

2. Gaede P, Vedel P, Larsen N, et al. Multifactorial intervention and cardiovascular disease in patients with type 2 diabetes. N EngI J Med 2003;348:383-93.

3. Gu K, Cowie CC, Harris MI. Diabetes and decline in heart disease mortality in US adults. JAMA I999;28I:I29I-7.

4. Haffner SM, Lehto S, Ronnemaa T, et al. Mortality from coronary heart disease in subjects with type 2 diabetes and in nondiabetic subjects with and without prior myocardial infarction. N Engl J Med I998;339:229-34.

5. Nichols GA, Brown JB. Unadjusted and adjusted prevalence of diagnosed depression in type 2 diabetes. Diabetes Care 2003;26:744-9.

6. Anderson RJ, Freedland KE, Clouse RE, et al. The prevalence of comorbid depression in adults with diabetes: a meta-analysis. Diabetes Care 2001;24:1069-78.

7. Gavard JA, Lustman PJ, Clouse RE. Prevalence of depression in adults with diabetes: an epidemiologic evaluation. Diabetes Care I993;16:II67-78.

8. Lustman PJ, Griffith LS, Gavard JA, et al. Depression in adults with diabetes. Diabetes Care I992;15:163I-9.

9. Remick RA. Diagnosis and management of depression in primary care: a clinical update and review. CMAJ 2002;167(II):1253-60.

Io. Parikh SV, Lam RW; CANMAT Depression Workgroup. Clinical guidelines for the treatment of depressive disorders, I. Definitions, prevalence and health burden. Can J Psychiatry 2001;46(Suppl I):13S-20S.

II. Egede LE. Effect of depression on work loss and disability bed days in individuals with diabetes. Diabetes Care 2004;27:I75I-3.

I2. Black SA, Markides KS, Ray LA. Depression predicts increased incidence of adverse health outcomes in older Mexican Americans with type 2 diabetes. Diabetes Care 2003;26:2822-8.

I3. Finkelstein EA, Bray JW, Chen $\mathrm{H}$, et al. Prevalence and costs of major depression among elderly claimants with diabetes. Diabetes Care 2003;26:415-20.

I4. de Groot M, Anderson R, Freedland KE, et al. Association of depression and diabetes complications: a meta-analysis. Psychosom Med 2001;63:619-30.

15. Egede LE, Zheng D, Simpson K. Comorbid depression is associated with increased health care use and expenditures in individuals with diabetes. Diabetes Care 2002; 25:464-70.

I6. Lin EH, Katon W, von Korff M, et al. Relationship of depression and diabetes selfcare, medication adherence, and preventative care. Diabetes Care 2004;27:2154-60.

I7. Ciechanowski PS, Katon WJ, Russo JE, et al. The relationship of depressive symptoms to symptom reporting, self-care, and glucose control in diabetes. Gen Hosp Psychiatry 2003;25:246-52.

I8. Ciechanowski PS, Katon WJ, Russo JE. Depression and diabetes: impact of depressive symptoms on adherence, function, and costs. Arch Intern Med 2000;160: 3278-85.

19. Lustman PJ, Anderson RJ, Freedland KE, et al. Depression and poor glycemic control: a meta-analytic review of the literature. Diabetes Care 2000;23:934-42.

20. Zhang X, Norris SL, Gregg EW, et al. Depressive symptoms and mortality among persons with and without diabetes. Am J Epidemiol 2005;161:652-60.

2I. Brown LC, Majumdar SR, Newman SC, et al. History of depression increases risk of diabetes in younger adults. Diabetes Care 2005;28:1063-7.

22. Arroyo C, Hu FB, Ryan LM, et al. Depressive symptoms and risk of type 2 diabetes in women. Diabetes Care 2004;27:129-33.

23. Everson-Rose SA, Meyer PM, Powell LH, et al. Depressive symptoms, insulin resistance, and risk of diabetes in women at midlife. Diabetes Care 2004;27:2856-62.

24. Golden SH, Williams JE, Ford DE, et al. Depressive symptoms and the risk of type 2 diabetes: the Atherosclerosis Risk in Communities study. Diabetes Care 2004;27:429-35.

25. Kumari M, Head J, Marmot M. Prospective study of social and other risk factors for incidence of type 2 diabetes in the Whitehall II Study. Arch Intern Med 2004;164:1873-80.

26. Palinkas LA, Lee PP, Barrett-Connor E. A prospective study of type 2 diabetes and depressive symptoms in the elderly: the Rancho Bernardo study. Diabet Med 2004; 2I:1185-9I. 
27. Van den Akker M, Schuurman A, Metsemakers J, et al. Is depression related to subsequent diabetes mellitus? Acta Psychiatr Scand 2004;IIO:I78-83.

28. Carnethon MR, Kinder LS, Fair JM, et al. Symptoms of depression as a risk factor for incident diabetes: findings from the National Health and Nutrition Examination Epidemiologic Follow-Up study, I97I-I992. Am J Epidemiol 2003;158:416-23.

29. Saydah SH, Brancati FL, Golden SH, et al. Depressive symptoms and the risk of type 2 diabetes in a US sample. Diabetes Metab Res Rev 2003;19:202-8.

3o. Kawakami N, Takatsuka N, Shimizu H, et al. Depressive symptoms and occurrence of type 2 diabetes among Japanese men. Diabetes Care i999;22:1071-6.

3I. Eaton WW, Armenian H, Gallo J, et al. Depression and risk for onset of type II diabetes: a prospective population-based study. Diabetes Care 1996;19:1097-I02.

32. Downey W, Beck P, McNutt M, et al. Health databases in Saskatchewan. In: Strom BL, ed. Pharmacoepidemiology, 3rd ed. Chichester: Wiley, 2000. p. 325-345.

33. Health Canada. First Report of the National Diabetes Surveillance System (NDSS). Ottawa: The Ministry; 2003.

34. Blanchard JF, Ludwig S, Wajda A, et al. Incidence and prevalence of diabetes mellitus in Manitoba, I986-I99I. Diabetes Care I996;19:807-Ir.

35. Hux JE, Ivis F, Flintoft V, et al. Diabetes in Ontario: determination of prevalence and incidence using a validated administrative data algorithm. Diabetes Care 2002; 25:512-6.

36. West SL, Richter A, Melfi CA, et al. Assessing the Saskatchewan database for outcomes research studies of depression and its treatment. JClin Epidemiol 2000;53 $823-31$

37. Pedhazur EJ. Multiple regression in behavioral research. Toronto: Harcourt Brace \& Company Canada, Ltd.; I997.

38. Reid R, Evans R, Barer M, et al. Conspicuous consumption: characterizing high users of physician services in one Canadian province. J Health Serv Res Policy 2003;8:215-24.

39. Bisschop MI, Kriegsman DM, Deeg DJ, et al. The longitudinal relation between chronic diseases and depression in older persons in the community: the Longitudinal Aging Study Amsterdam. JClin Epidemiol 2004;57:187-94.
40. Frasure-Smith N, Lesperance F, Talajic M. Depression following myocardial infarction: impact on 6-month survival. JAMA I993;270:1819-25

4I. Parikh RM, Robinson RG, Lipsey JR, et al. The impact of poststroke depression on recoveries in activities of daily living over a 2-year follow-up. Arch Neurol I990;47:785-9.

42. Brown LC, Johnson JA, Majumdar SR, et al. Evidence of suboptimal management of cardiovascular risk in patients with type 2 diabetes and symptomatic atherosclerosis. CMAJ 2004;171(I0):II89-92.

43. Polsky D, Doshi JA, Marcus S, et al. Long-term risk for depressive symptoms after a medical diagnosis. Arch Intern Med 2005;165:126o-6.

44. Engum A, Mykletun A, Holen A, et al. Depression and diabetes: a large populationbased study of sociodemographic, lifestyle, and clinical factors associated with depression in type I and type 2 diabetes. Diabetes Care 2005;28:1904-9.

Correspondence to: Dr. Jeffrey A. Johnson, Institute of Health Economics, I0405 Jasper Ave., Rm. I200, Edmonton AB $\mathrm{T}_{5} \mathrm{~J}_{3} \mathrm{~N}_{4}$ fax 780 448-oor8; jeff.johnson@ualberta.ca

Appendix 1: Oral antidiabetic agents

- Acarbose

- Glyburide

- Repaglinide

- Acetohexamide

- Metformin

- Rosiglitazone

- Chlorpropamide

- Nateglinide

- Tolbutamide

- Gliclazide
The complete picture on research. MORE COMPREHENSIVE THAN EVER.

CMAJ's reputation and wide Canadian and international reach make it THE place to publish leading Canadian research. CMAJ publishes important peer-reviewed research within weeks of submission and ranks fifth among international general medical journals by impact factor, a measure of the scientific importance of a journal.

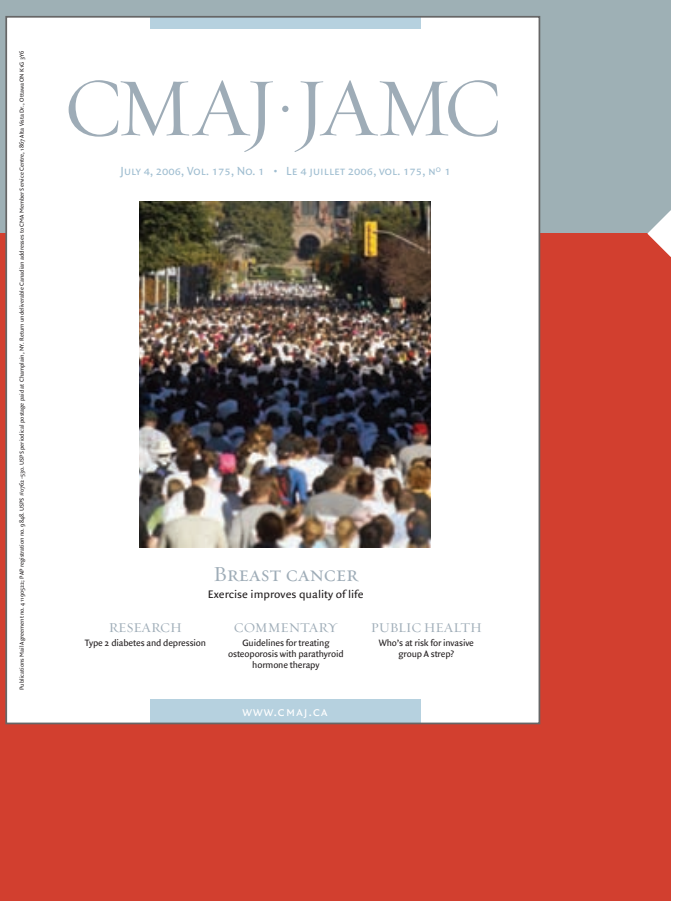

The essential read. ${ }^{\mathrm{TM}}$ 